\title{
Effect of Output Bar Supporting Methods on High Velocity Tensile Behavior for Steel Plate*
}

\author{
Masaaki ITABASHI ${ }^{* *}$ \\ **Department of Mechanics and Systems Design, Tokyo University of Science, Suwa, \\ 5000-1 Toyohira, Chino, Nagano 391-0292, Japan \\ E-mail: itabashi@rs.suwa.tus.ac.jp
}

\begin{abstract}
In order to obtain precise and correct dynamic stress-strain behavior for steel plate, the split Hopkinson (Kolsky) bar method or the one bar method has been adopted as a testing method. In these two methods, a dynamic load transducer is the thin steel bar(s). On the input and output bars, typically two or four strain gages are adhered at the same distance from the end of the bars to detect elastic strains of the bars as dynamic load signal. The bars are usually mounted on simple supports, allowing a little axial elongation of the bars. Then, ball bearings or polytetrafluoroethylene parts are frequently installed between the bars and supports, because the friction between them will affect the quality of the dynamic load signal. On the other hand, only for the one bar method, it is reported that a relatively tight support, neighboring the loading end of the output bar, is effective to reduce an extraordinarily-high initial stress peak on dynamic stress-strain curve. In this paper, some trials have been carried out to find the optimum supporting condition for the output bar loading end in the one bar method. An assembly for a steel plate specimen is connected to an impact block. The other end of the assembly is an extension of the output bar. Usually, from the end of gage length of the specimen plate, there is no output bar support within approximately $650 \mathrm{~mm}$, for the present apparatus. This situation is designated as "no support". At a location of $60 \mathrm{~mm}$ from the end of the gage length, a simple output bar support is introduced additionally. This situation is called as "simple support", because the output bar is left on the V-shaped top of the support. Additional upper supporting parts can be installed to the simple support condition. After the installation, a square hole is formed on the top of the support. The output bar touches four sides of the hole. This situation is called as "surrounding support". In addition, specimen assembly types are also included in experimental conditions. Shapes of obtained stress-strain curves in each experimental condition are mutually compared. Also they are compared with that of a reference curve which has the quality of interchangeable with the curves obtained by the split Hopkison bar method. Two experimental conditions are recommended to detect acceptable stress-strain relationships for steel plate.
\end{abstract}

Key words: High Velocity Tensile Behavior, Strain Rate, One Bar Method, Split Hopkinson Bar Method, Output Bar, Supporting Method

\section{Introduction}

Dynamic tensile test method at the strain rate of $1 \times 10^{3} \mathrm{~s}^{-1}$ for metallic materials has not been established yet, as an industrial standard. From car companies and steel companies who are supplying their steel sheet to the car companies, such a standard is eagerly

*Received 1 Sep., 2008 (No. 08-0644) [DOI: 10.1299/jmmp.3.295] 
requested to improve the safety of occupants and pedestrians in an accident. There are several candidates to be adopted as recommended test methods. The most effective and well-known candidates are the tensile version of the split Hopkinson (Kolsky) bar method ${ }^{(1)}$ and the one bar method ${ }^{(2)}$.

The first systematic trial to obtain dynamic behavior of Al alloy and steel plates was made by Nakanishi, Itabashi and Kawata ${ }^{(3)}$. They mounted a plate specimen assembly, as shown in Fig. 1, to their horizontal slingshot machine ${ }^{(4)}$ by a pin fastening at load-input end (the right-hand side in Fig. 1) and a screw fastening at load-output end (left-hand side). The plate was strengthened at a spot-welded tab and adhered to a steel attachment by epoxy adhesive. Each stress-strain curve for a series of Al alloys possessed a tremendous initial peak. Moreover, for a series of steels each yield point was inordinately high. The unexpected peaks were not acceptable as a dynamic property of the Al alloys and steels.

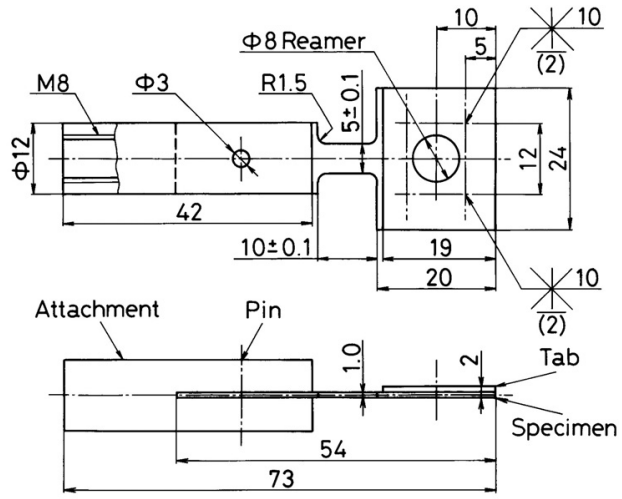

Fig. 1 Old specimen assembly

In the 1999-2001 fiscal years, round robin tests of various high velocity tensile test methods at a strain rate of $1 \times 10^{3} \mathrm{~s}^{-1}$ for two steels (IF steel and $440 \mathrm{MPa}$ grade steel) and 7075-T6 Al alloy of $1 \mathrm{~mm}$ thickness were carried out by five Japanese universities and five Japanese steel companies, as a national project ${ }^{(5-7)}$. In this project, it was confirmed that obtained experimental results by the one bar method and those by the split Hopkinson pressure bar method were interchangeable, as a result ${ }^{(7,8)}$. In order to reach the interchangeability, a new design of the specimen assembly was needed for steel plate, as shown in Fig. 2. For this type of the assembly, both ends of the specimen plate were adhered to two steel attachments. On the other hand, another machine which is adopting the one bar method in Nippon Steel Corporation did attain to the interchangeability by suppressing lateral vibration of the output bar loading end, for the old specimen assembly ${ }^{(9)}$. The output bar itself is not perfectly straight, since its length is several meters. In Ref. (9), Yoshida et al. assumed the lateral amplitude of the load-input end of the output bar by several tens of micrometers. In their numerical simulation, a tremendous initial peak was reproduced on an

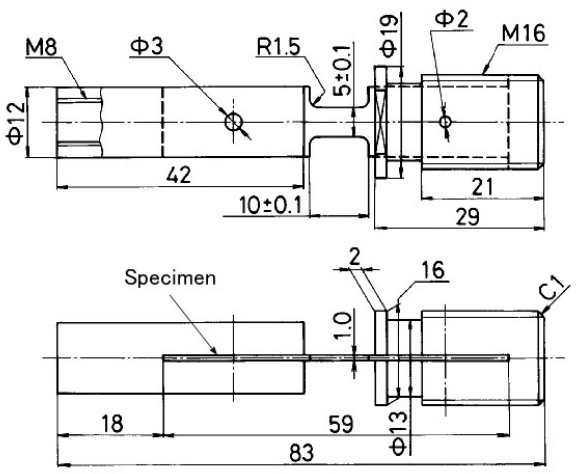

Fig. 2 New specimen assembly 
assumed dynamic stress-strain curve, with the misalignment of the output bar end. So, ideal alignment of the output bar was tried to realize experimentally by setting the additional support near the output bar end. They have succeeded in obtaining acceptable dynamic stress-strain curves of the same steel plate which is investigated in the national project, even for the old specimen assembly.

In this paper, in order to obtain acceptable stress-strain curves for steel plate, the optimum experimental condition is explored with varying both the output bar supporting methods and the types of the specimen assembly, for the testing machine in Tokyo University of Science, Suwa. The height of initial peak, strain at lower yield point, tensile strength, breaking strain, stability of stress-stain curves and FFT power spectrum are selected as criteria of the acceptability.

\section{Experimental Method}

\subsection{Specimen Plate}

Specimen plates of $440 \mathrm{MPa}$ grade steel were distributed in the national project, as plates of $1.0 \mathrm{~mm}$ in thickness. The chemical compositions are Fe-0.061C-0.03Si-0.60Mn$0.136 \mathrm{P}-0.012 \mathrm{~S}-0.052 \mathrm{Al}-0.004 \mathrm{~N}$ (in mass \%). The axial direction of the specimen is aligned with the rolling direction of the plate.

\subsection{Specimen Assembly Preparation}

Both types of the specimen assembly (Figs. 1 and 2) are investigated. The adhesive has been changed to toughened acrylic adhesive, Pegalock G (\#9203), Koatsu Gas Kogyo Co., Ltd. This adhesive is cured at room temperature.

\subsection{One Bar Method}

The principle of the one bar method ${ }^{(2)}$ is shown in Fig. 3. It consists of three elements, an impact block as a rigid body, a specimen and the output bar as an elastic bar. Deriving from one-dimensional elastic wave propagation theory and Hooke's law, the fundamental formulae for dynamic stress $\sigma(t)$, dynamic strain $\varepsilon(t)$ and strain rate $\dot{\varepsilon}(t)$ in nominal are as follows:

$$
\begin{aligned}
& \sigma(t)=\frac{S_{0}}{S} E_{0} \varepsilon_{g}\left(t+\frac{a}{c}\right) \\
& \varepsilon(t)=\frac{1}{\ell} \int_{0}^{t}\left\{V(\tau)-c \varepsilon_{g}\left(\tau+\frac{a}{c}\right)\right\} d \tau \\
& \dot{\varepsilon}(t)=\frac{1}{\ell}\left\{V(t)-c \varepsilon_{g}\left(t+\frac{a}{c}\right)\right\}
\end{aligned}
$$

where $t$ is time after impact between the impact block and a hammer, $\ell$ and $S$ are the length and cross-sectional area of the specimen, $S_{0}, E_{0}$ and $c$ are the cross-sectional area, Young's modulus and longitudinal elastic wave velocity of the output bar, and $V(t)$

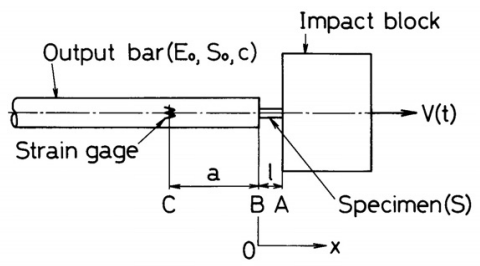

Fig. 3 Principle of the one bar method 
and $\varepsilon_{g}(t)$ are the velocity of the impact block and the strain of the output bar at the distance $a$ from the load input end.

From the split Hopkinson bar users' view, the accuracy of Eq. (1) was not guaranteed by confirming the equivalency between the acting forces on both ends of the specimen. By assuming the rigidity of the impact block, Eq. (1) can be derived. Experimentally, the obtained dynamic tensile stress-strain curves by the split Hopkinson bar method and the one bar method at the strain rate of $1 \times 10^{3} \mathrm{~s}^{-1}$, for IF steel and 7075-T6 Al alloy, were interchangeable ${ }^{(7,8)}$. Therefore, Eq. (1) is valid for ductile metallic materials.

Dynamic tensile load is generated by a horizontal slingshot machine ${ }^{(4)}$. The wheeled hammer made of carbon steel, $50 \mathrm{~kg}$ in mass, can be accelerated to the velocity of $5-6 \mathrm{~m} / \mathrm{s}$. The accelerated hammer impinged on the impact block made of chromium molybdenum steel. The impact block of $0.7 \mathrm{~kg}$ in mass and $20(\mathrm{H}) \times 60(\mathrm{~L}) \times 75(\mathrm{~W}) \mathrm{mm}^{3}$ in size, flies at the higher velocity, typically $6-7 \mathrm{~m} / \mathrm{s}$, than that of the hammer. Therefore, the maximum nominal strain rate attained $0.6 \times 10^{3}-0.7 \times 10^{3} \mathrm{~s}^{-1}$ with the specimen of the initial gage length of $10 \mathrm{~mm}$.

\subsection{High Velocity Tensile Testing Machine}

Figure 4 shows a block diagram of the dynamic data acquisition system. In order to detect $\varepsilon_{g}(t)$, four semiconductor strain gages (Kyowa KSP-2-120-E3, gage length: 2mm, gage factor: 120) are cemented onto the output bar made of type 304 stainless steel, at the location of $102 \mathrm{~mm}(=a)$ apart from the load input end (Strictly speaking, the input end of the thinner attachment of the specimen assembly.). The output bar is approximately $3 \mathrm{~m}$ in length and $\phi 12 \mathrm{~mm}$ in diameter. The displacement of the impact block $x(t)$ was detected by an electro-optical displacement transducer (Zimmer Model 100D/II, gage length of an installed lens: $10 \mathrm{~mm}$ ). The accuracy of this transducer is $\pm 0.2 \%$ of the gage length of the installed lens, $\pm 20 \mu \mathrm{m}$. This signal is differentiated with respect to time by a differentiator (Zimmer Model 131C) to obtain the velocity of the block $V(t)$. Two signals, $\varepsilon_{g}(t)$ and $V(t)$ are stored in two synchronized digital memories (Kawasaki Electronica TMR-100, sampling frequency: $1 \mathrm{MHz}$, resolution: 10bits, memory length: 4kwords).

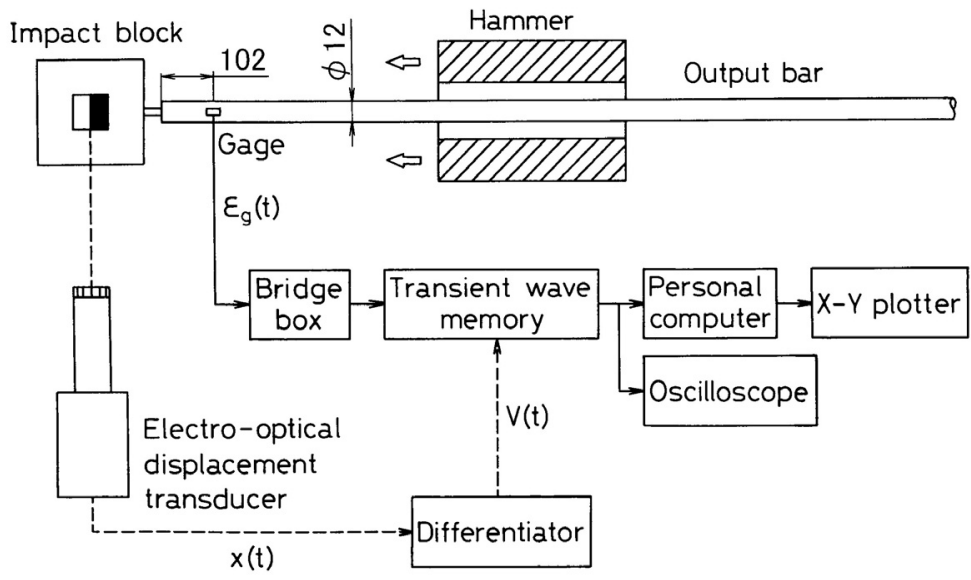

Fig. 4 Block diagram of dynamic data acquisition system for tensile stress-strain relation

Typical traces of $\varepsilon_{g}(t)$ and $V(t)$ are shown in Fig. 5. The experiment is carried out with the no support and new specimen assembly. In this diagram, specimen deformation up to fracture continues over $700 \mu \mathrm{s}$, approximately. It is worthy to note that the rise time of $V(t)$ is $100 \mu$ s or below. Comparing with the split Hopkinson bar method, the rise time is 5-10 times longer. For this experiment, the maximum strain rate is evaluated as $566 \mathrm{~s}^{-1}$.

In this series of experiments, a representative nominal strain rate is the maximum 


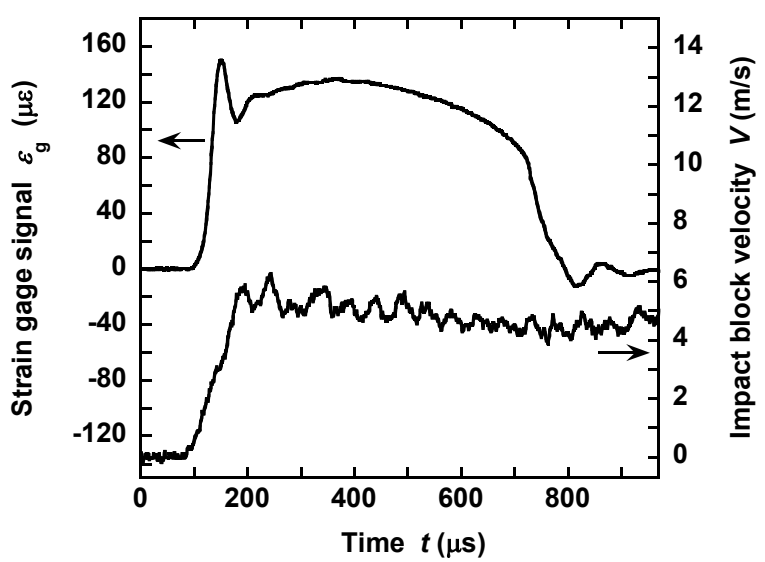

Fig. 5 Typical traces of strain gage signal and impact block velocity

value, because the maximum strain rate is relatively close to the instant of the maximum value of $\varepsilon_{g}(t)$.

\subsection{Additional Supporting Method}

The load-input end of the output bar is set on the additional support. Schematic axial views of the supports and the output bar are shown in Fig. 6. As mentioned previously, there are three types of the supporting method, the no support, simple support and surrounding support. Surfaces of the supports contacting with the output bar are rounded at the radius of curvature of $2 \mathrm{~mm}$ so that the contact points of them are very small. The distance between the load-output end of the gage length and the contact points is about $60 \mathrm{~mm}$.

Photographs of the surrounding support with the old and new specimen assemblies are shown in Figs. 7 and 8, respectively.

The most important thing to be considered in setting the surrounding support is

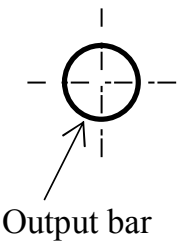

(a) No support

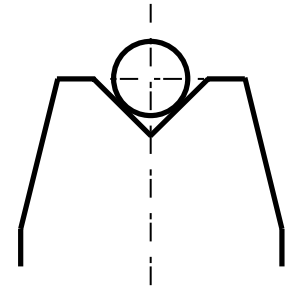

(b) Simple support

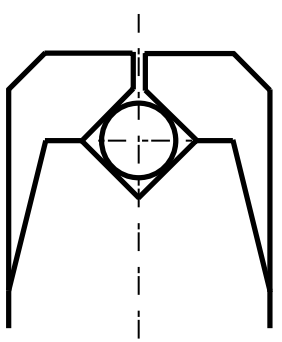

(c) Surrounding support

Fig. 6 Types of additional supporting method

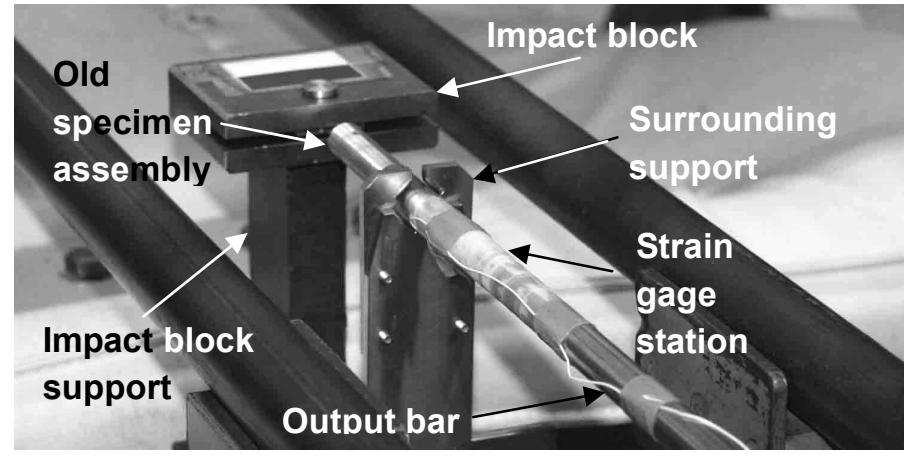

Fig. 7 Surrounding-supported output bar with old specimen assembly 


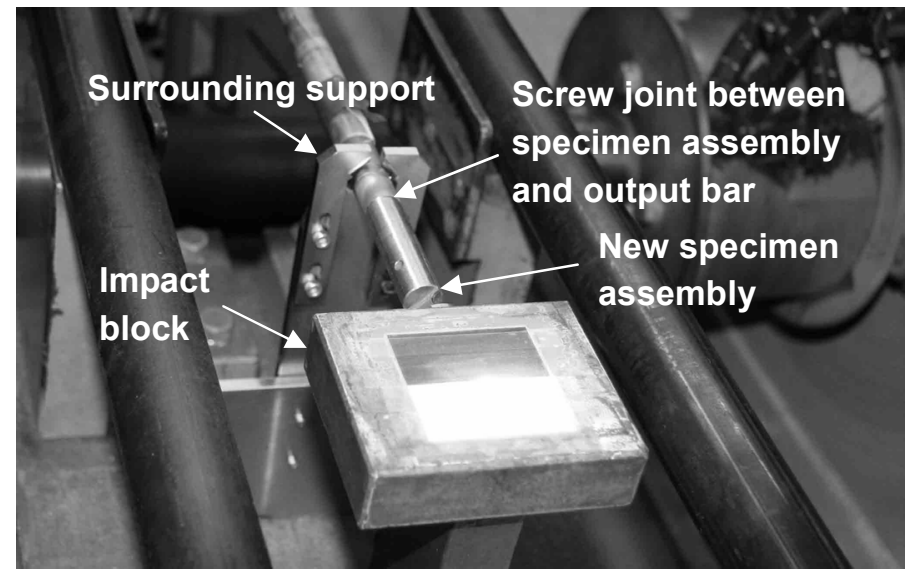

Fig. 8 Surrounding-supported output bar with new specimen assembly

avoidance of too much tight contact. If the contact force between the output bar and the support was too much tight, the axial movement of the bar would be constrained and the dynamic force measurement would be suffered from some reduction. Then, at each preparation for the present series of tensile tests, the support is tightened properly to allow almost free axial movement of the output bar.

\subsection{Dynamic Tensile Tests and Data Analyses}

Dynamic tensile tests are repeated three times for each experimental condition. The supporting methods have three variations and the types of specimen assemblies have two. The number of combinations of them is six. Dynamic tensile stress-strain curves and strain rate-time relationships are reduced by Eqs. (1)-(3), as usual.

According to the experience in Ref. (8), discrete Fourier transform ${ }^{(10)}$ of the obtained stress-time curves is tried to find longitudinal resonance of the assembled part(s) of the testing machine and the specimen assembly. Analyzed frequency range is $10-500 \mathrm{kHz}$ so that the body length of $5-250 \mathrm{~mm}$ can be detected as the resonant source. When there is an extraordinarily-high initial peak on a stress-time curve, a broad small peak at $50-80 \mathrm{kHz}$ appears on the stress amplitude-frequency curve. In the case of the old specimen assembly, three possible body lengths of the corresponding longitudinal frequency, $50-80 \mathrm{kHz}$, were found. The new specimen assembly was designed to eliminate the resonant body lengths around the pin joint between the impact block and the tabbed specimen end of the old assembly. So, the frequency range $50-80 \mathrm{kHz}$ is a detective range of the occurrence of the tremendous stress peak.

\section{Results and Discussion}

The specimen plate, $440 \mathrm{MPa}$ grade steel indicates its mechanical behavior as shown in Fig. 9. The dynamic strain rate is $0.7 \times 10^{3} \mathrm{~s}^{-1}$ and quasi-static rate $1 \times 10^{-3} \mathrm{~s}^{-1}$. The dynamic curve is interchangeable with those obtained by the split Hopkinson bar method. For the dynamic curve, the height of initial peak is around $700 \mathrm{MPa}$, tensile strength $600 \mathrm{MPa}$, breaking strain $30 \%$, and strain at lower yield point $1 \%$. Hereafter, this curve is a reference of dynamic behavior of 440MPa grade steel.

Figure 10 shows three dynamic stress-strain curves for the old specimen assembly with the no support condition. Reproducibility is quite low. Tensile strengths of Nos.3 and 4 curves are below 600MPa and that of No.11 is approximately 700MPa. No.4 curve has a relatively large strain at lower yield stress. This experimental condition is not acceptable for dynamic tensile test. 


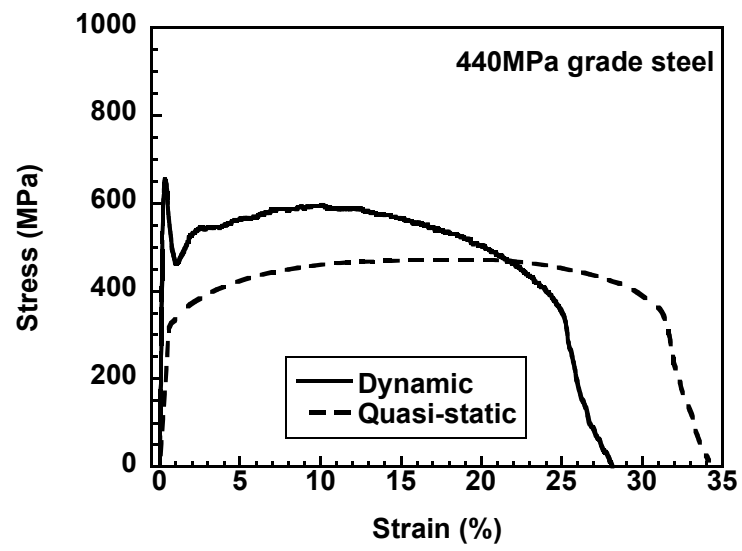

Fig. 9 Dynamic and quasi-static mechanical behavior of investigated 440MPa grade steel

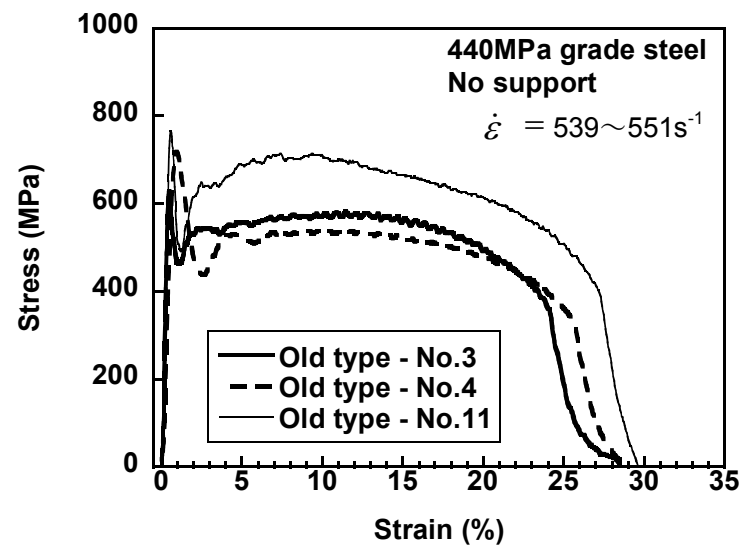

Fig. 10 Dynamic stress-strain curves for the old specimen assembly with no support condition

The representative strain rate range indicated in this diagram is that of the maximum strain rate values. In Eqs. (2 and 3), the length of the specimen, $\ell$ includes round fillets at the both ends of the parallel part. For this treatment, the representative strain rate gives a slightly lower value of the real strain rate.

On the other hand, for the new specimen assembly, reproducibility is relatively good, as shown in Fig. 11. Though No.3 curve indicates smaller flow stress than Nos.1 and 2, it is within an acceptable range in dynamic tension. The heights of initial peak are below $700 \mathrm{MPa}$ and the strains at lower yield stress are 1\%. Breaking strains are around $30 \%$.

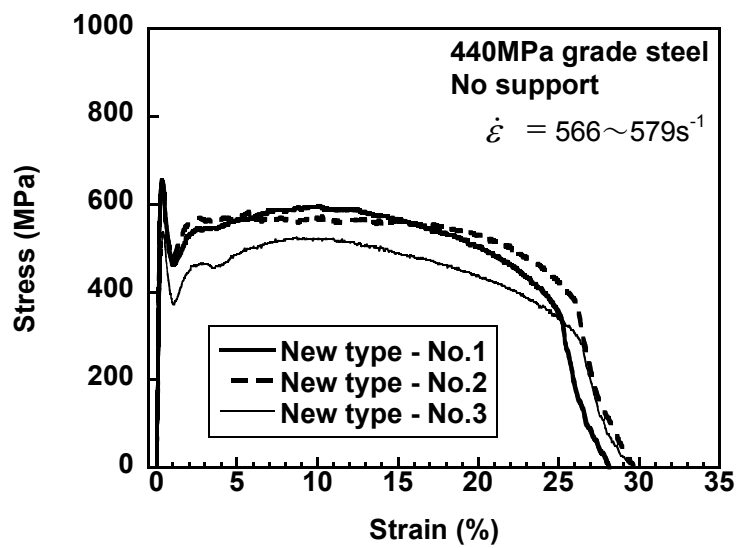

Fig. 11 Dynamic stress-strain curves for the new specimen assembly with no support condition 
Figures 12 and 13 show results of frequency spectrum analyses of dynamic stress-time relations. Upper two curves are vertically shifted by $1000 \mathrm{MPa}$ and $2000 \mathrm{MPa}$, respectively. The small broad peak, $60-70 \mathrm{kHz}$, is found on each curve in Fig. 12 and not found in Fig. 13. Then, the peak plays a role of an indicator for the occurrence of the extraordinarily-high stress peak on the obtained stress-strain curve. The fact was also observed with the present testing machine in the national project ${ }^{(7,8)}$.

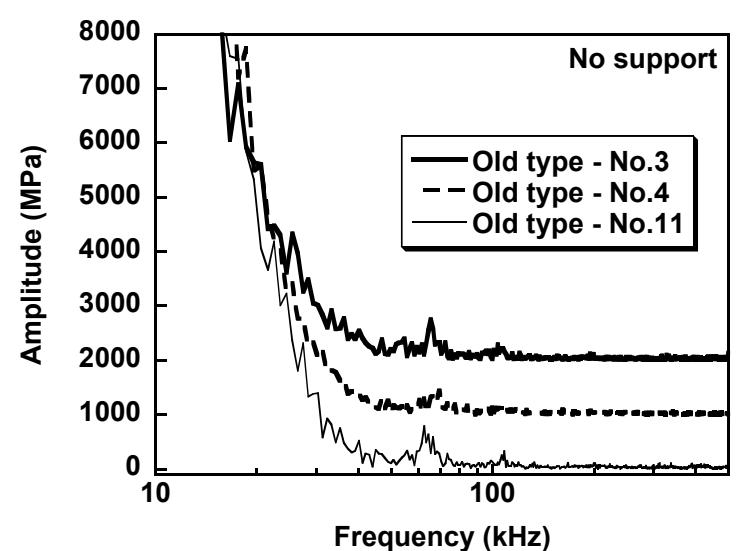

Fig. 12 Power spectra of stress-time curves for the old specimen with no support condition

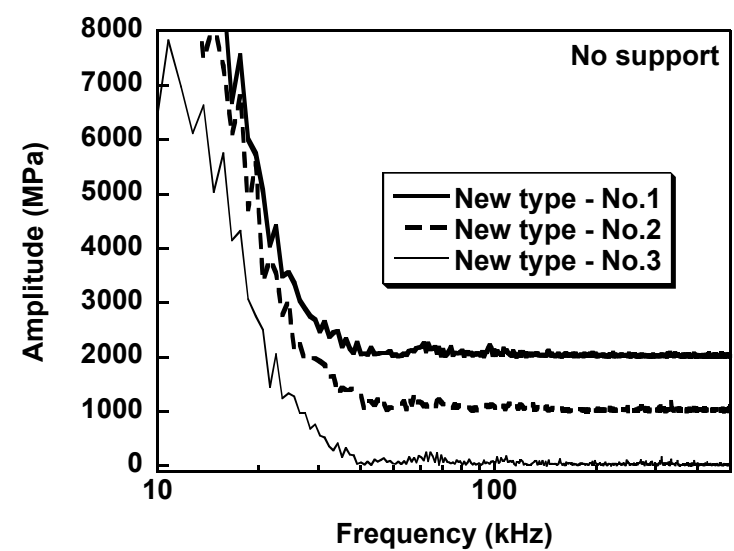

Fig. 13 Power spectra of stress-time curves for the new specimen with no support condition

With the simple support, for the old specimen assembly, the curves in Fig. 14 are improved, because especially tensile strengths are almost $600 \mathrm{MPa}$. For the new specimen assembly, only No.4 curve in Fig. 15 has the strain at lower yield point is $2 \%$. However, the

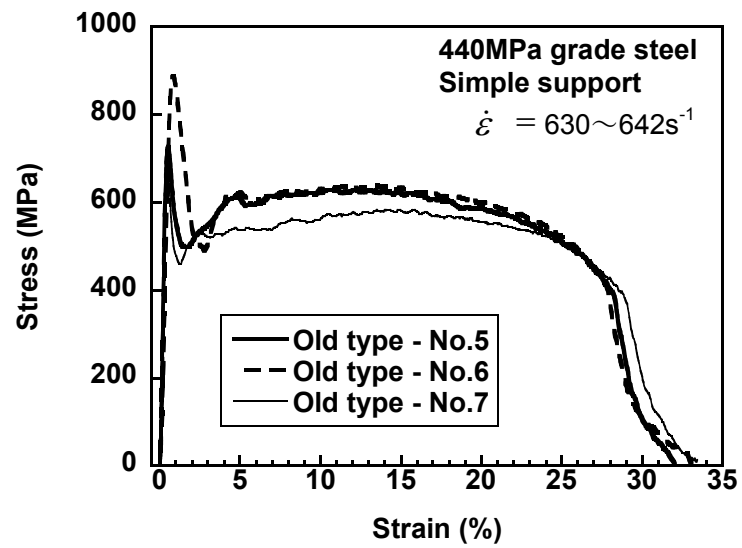

Fig. 14 Dynamic stress-strain curves for the old specimen assembly with simple support condition 


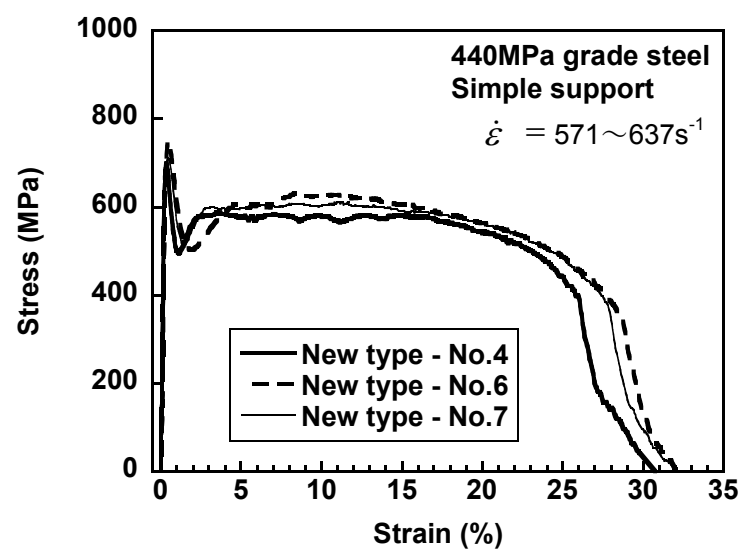

Fig. 15 Dynamic stress-strain curves for the new specimen assembly with simple support condition

height of the initial peak is relatively low.

The power spectrum analyses are shown in Figs. 16 and 17, with the simple supporting method. In Fig. 16, only No.6 has a small broad peak. Refer to Fig. 14. The stress-strain curve of No.6 has an extraordinarily-high initial stress peak, around 900MPa and a large strain value at lower yield stress, $3 \%$. Then, this FFT treatment is confirmed as the indicator of the tremendous initial peak on a stress-strain curve, again. On the other hand, in Fig. 17, no broad small peak is found at the frequency range of $50-80 \mathrm{kHz}$ so that, in Fig. 15, the magnitude of initial peaks are acceptable.

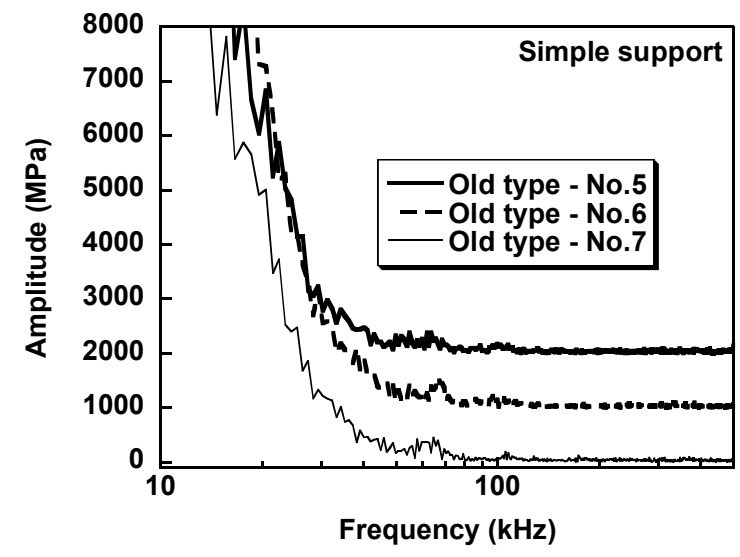

Fig. 16 Power spectra of stress-time curves for the old specimen with simple support condition

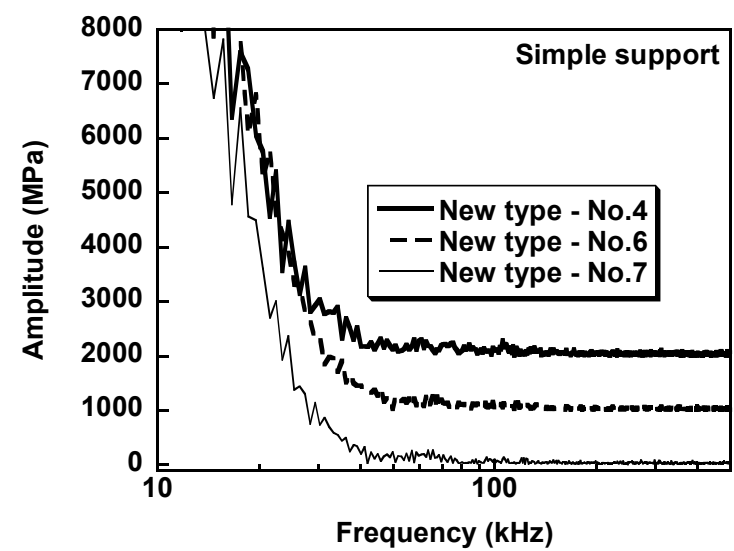

Fig. 17 Power spectra of stress-time curves for the new specimen with simple support condition 
Figure 18 indicates the dynamic stress-strain curves with the old specimen assembly for the surrounding support. A perfect reproducibility is shown in this diagram. However, unfortunately, the magnitude of initial peaks is not acceptable; the tensile strengths are too high, 700MPa. Figure 19 indicates the curves for the new specimen assembly. The breaking strains is scattered very much. Also the tensile strengths are too high as the same as that of the curves for the old specimen assembly.

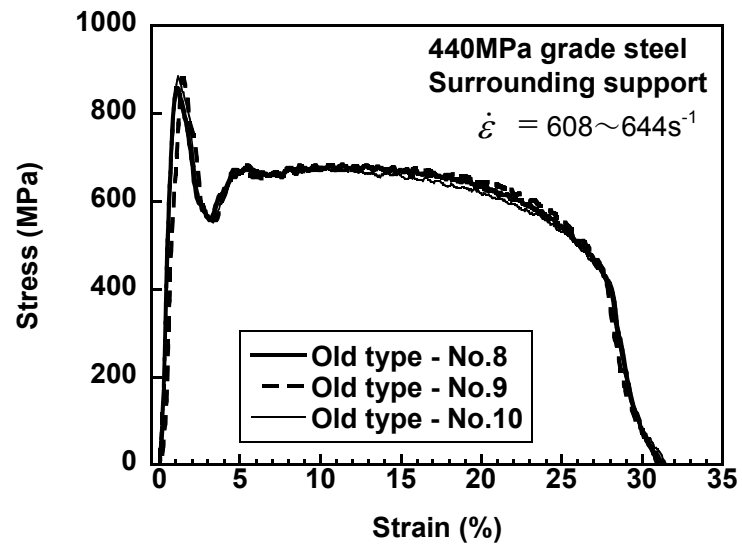

Fig. 18 Dynamic stress-strain curves for the old specimen assembly with surrounding support condition

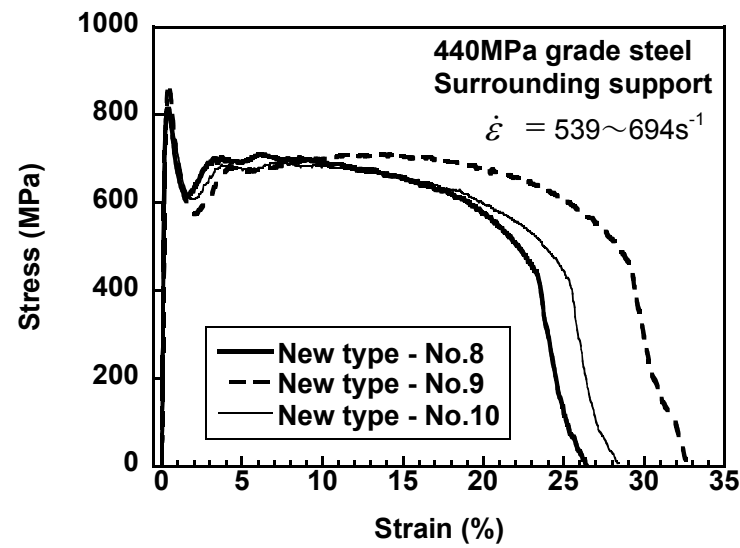

Fig. 19 Dynamic stress-strain curves for the new specimen assembly with surrounding support condition

The results of the FFT analysis are shown in Figs. 20 and 21. The former figure has the peaks at $50-80 \mathrm{kHz}$. But, the latter figure possesses almost no peak. The reason may be concluded as the difference of the strains at lower yield stress between the old and new specimen assemblies. For the old assembly, the strain is 3\%. On the other hand, for the new assembly, it is $1.5-2 \%$. The FFT analysis is more sensitive with respect to time (equivalent to the strain value). Effect of the height of initial peak on the FFT analysis is relatively low.

Therefore, the apparent effects of the output bar supporting methods and the types of the specimen assemblies on the obtained high velocity mechanical properties of $440 \mathrm{MPa}$ grade steel are not negligible. The experimental results of the no support and simple support have almost the same tendencies about the six viewpoints, the height of initial peak, strain at lower yield point, tensile strength, breaking strain, stability of stress-strain curves and FFT power spectrum. The observed difference between the two supporting methods is based on the types of the specimen assembly. The new specimen assembly shows better quality than the old one. This is not the same results in Ref. (9). Yoshida et al. concluded that even the old specimen assembly could give the acceptable dynamic stress-strain curves for steel plate. 


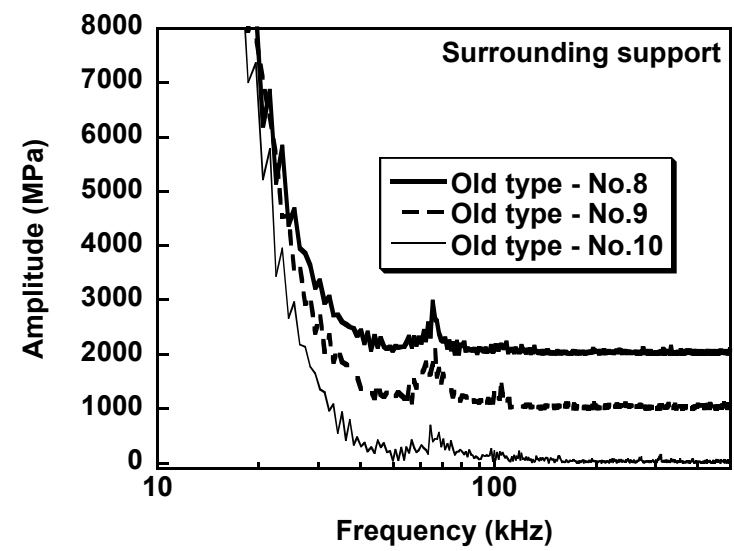

Fig. 20 Power spectra of stress-time curves for the old specimen with surrounding support condition

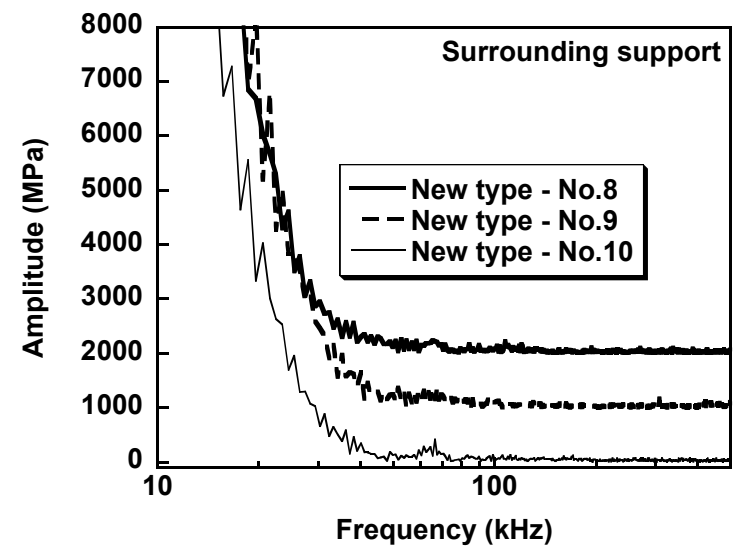

Fig. 21 Power spectra of stress-time curves for the new specimen with surrounding support condition

Originally, it was thought that the most excellent supporting method is the surrounding support. The support gives the two-dimensional constraint with allowing axial slide of the output bar. In fact, some extra energy is consumed during the dynamic tensile tests, at the support. Especially, the obtained height of initial peak and tensile strength are too high, regardless of the specimen assembly. As the cause of this phenomenon, some possible problems about the surrounding supporting method have been tried to explain the results shown in Table 1. In addition, the apparent absorbed energy during deformation is evaluated from the area under the stress-strain curve. The average values are shown in Fig. 22. The extra energy may be a measure of the stress increase, because the breaking strains are almost constant.

The tried possible problems are the following three, friction between the output bar and surrounding support, deflection of the support stand and deflection of the output bar.

From the experimental data, total slide between the output bar and support is only $0.4 \mathrm{~mm}$ in maximum. The frictional energy is negligibly small, $0.012 \mathrm{~J}$.

The deflection of the support stand is roughly evaluated. The support stand is made of steel plate of $4 \mathrm{~mm}$ in thickness, and of $16 \mathrm{~mm}$ in width. When the output bar is stuck to the support, the support stand is deflected to the specimen loading direction. The deflection energy is only $0.0020 \mathrm{~J}$.

The output bar is not straight perfectly. Typical deflection at the load-input end is $0.5 \mathrm{~mm}$. Here, a cantilever model is assumed. The length of the cantilever is $60 \mathrm{~mm}$. The value is equivalent to the overhanged output bar length from the surrounding support plus the attachment length. The deflection is typically $0.5 \mathrm{~mm}$. The deflection energy of the 
Table 1 The summary of the experimental results (circle: excellent, triangle: acceptable, cross: not acceptable)

\begin{tabular}{|c|c|c|c|c|c|c|}
\hline & \multicolumn{2}{|c|}{ No support } & \multicolumn{2}{|c|}{ Simple support } & \multicolumn{2}{|c|}{$\begin{array}{l}\text { Surrounding } \\
\text { support }\end{array}$} \\
\hline & $\begin{array}{l}\text { Old } \\
\text { assy. }\end{array}$ & $\begin{array}{l}\text { New } \\
\text { assy. }\end{array}$ & $\begin{array}{l}\text { Old } \\
\text { assy. }\end{array}$ & $\begin{array}{l}\text { New } \\
\text { assy. }\end{array}$ & $\begin{array}{l}\text { Old } \\
\text { assy. }\end{array}$ & $\begin{array}{l}\text { New } \\
\text { assy. }\end{array}$ \\
\hline $\begin{array}{l}\text { Height of initial } \\
\text { peak }\end{array}$ & $\triangle$ & $\mathrm{O}$ & $\triangle$ & $\mathrm{O}$ & $x$ & $x$ \\
\hline $\begin{array}{l}\text { Strain at lower } \\
\text { yield point }\end{array}$ & $x$ & $\mathrm{O}$ & $x$ & $\triangle$ & 0 & $\triangle$ \\
\hline $\begin{array}{l}\text { Tensile } \\
\text { strength }\end{array}$ & $\triangle$ & $\mathrm{O}$ & O & O & $\triangle$ & $\triangle$ \\
\hline Breaking strain & O & $\mathrm{O}$ & O & $\mathrm{O}$ & $\mathrm{O}$ & $x$ \\
\hline $\begin{array}{l}\text { Stability of s-s } \\
\text { curves }\end{array}$ & $x$ & $\triangle$ & $\triangle$ & O & O & $x$ \\
\hline $\begin{array}{l}\text { FFT power } \\
\text { spectrum }\end{array}$ & $x$ & $\mathrm{O}$ & $\triangle$ & $\mathrm{O}$ & $x$ & $\triangle$ \\
\hline
\end{tabular}

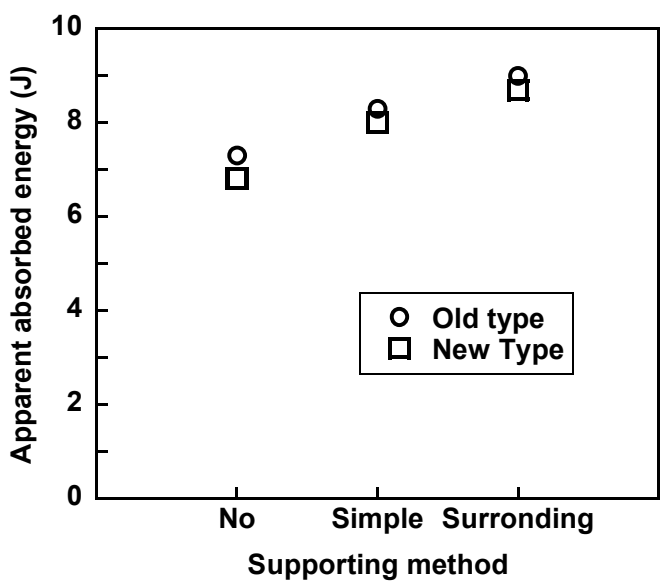

Fig. 22 Means of apparent absorbed energy

output bar is evaluated as $0.83 \mathrm{~J}$. This is the same order of the energy difference between the simple support and surrounding support in Fig. 22. So, if a perfectly-straight output bar was used in this series of experiment, the surrounding support would give better results.

\section{Conclusions}

Three types of the output bar supporting methods and two types of the specimen assembly are tried in dynamic tensile test for 440MPa grade steel plate. From the viewpoint of the height of initial peak, strain at lower yield point, tensile strength, breaking strain, stability of stress-strain curves and discrete FFT power spectrum, the quality of the obtained dynamic stress-strain curves is evaluated. Recommended experimental conditions are the following two, using the new specimen assembly with the no support, and with simple support. 


\section{Acknowledgment}

The present author would like to thank the contribution of undergraduate students of Tokyo University of Science, Suwa, Mr. Koji Ohtsuki and Mr. Yuichi Takeuchi, for carrying out many experiments.

\section{Reference}

(1) Kolsky, H., An Investigation of the Mechanical Properties of Materials at Very High Rates of Loading, The Proceedings of the Physical Society, Section B, Vol.62, (1949), pp.676-700.

(2) Kawata, K., Hashimoto, S., Kurokawa, K. and Kanayama, N., A New Testing Method for the Characterization of Materials in High Velocity Tension, Mechanical Properties at High Rates of Strain 1979, (J. Harding, ed.), (1979), pp.71-80, Institute of Physics, Bristol and London.

(3) Nakanishi, E., Itabashi, M. and Kawata, K., The Fast and Slow Deformation Behaviour in Commercial Aluminum Alloy and Steel Sheets for Automotive Bodies, H. P. Rossmanith, ed., Structural Failure, Product Liability and Technical Insurance, IV, (1993), pp.423-430, Elsevier Science Publishers BV.

(4) Itabashi, M. and Kawata, K., Carbon Content Effect on High-Strain-Rate Tensile Properties for Carbon Steels, International Journal of Impact Engineering, Vol.24, (2000), pp.117-131.

(5) The Committee for Research and Development of Standard Testing Method of Metallic Materials at High Strain Rates, ed., Operating Results Report of Research and Development of Standard Testing Method for Metallic Materials at High Strain Rates in the 1999 Fiscal Year (in Japanese), (2000), The New Material Center, The Foundation of Osaka Science and Technology Center.

(6) The Committee for Research and Development of Standard Testing Method of Metallic Materials at High Strain Rates, ed., Operating Results Report of Research and Development of Standard Testing Method for Metallic Materials at High Strain Rates in the 2000 Fiscal Year (in Japanese), (2001), The New Material Center, The Foundation of Osaka Science and Technology Center.

(7) The Committee for Research and Development of Standard Testing Method of Metallic Materials at High Strain Rates, ed., Operating Results Report of Research and Development of Standard Testing Method for Metallic Materials at High Strain Rates in the 2001 Fiscal Year (in Japanese), (2002), The New Material Center, The Foundation of Osaka Science and Technology Center.

(8) Itabashi, M., High Velocity Tensile Test for Thin Plate Specimen with One Bar Method, JSME International Journal, Series A, Vol.46, (2003), pp.316-321.

(9) Yoshida, H., Kuriyama, Y., Uenishi, A. and Takahashi, M., Exact Identification of Strain Rate Dependency of Steel Properties by One Bar Method (in Japanese), Preprint of JSAE Annual Congress, 20025235, (2002).

(10) Mitani, M., Digital Filter Design (in Japanese), (1987), pp.48-49, Shokodo, Tokyo. 